\title{
Vitrification: the pioneering past to current trends and perspectives of cryopreserving human embryos, gametes and reproductive tissue
}

This article was published in the following Dove Press journal:

Journal of Biorepository Science for Applied Medicine

6 September 2017

Number of times this article has been viewed

\author{
Mitchel C Schiewe \\ Robert E Anderson \\ Ovation Fertility/Southern California \\ Center for Reproductive Medicine, \\ Newport Beach, CA, USA
}

\begin{abstract}
After more than 2 decades of development in mammalian models and the clinical focus of a few pioneering laboratories, vitrification of human oocytes and embryos has transformed today's assisted reproductive technology (ART) industry. Our ability to cryopreserve gametes and embryos without fear of the damaging effects of ice formation has instilled great confidence in post-warming specimen viability. In turn, clinical treatment options are progressively eliminating fresh embryo transfer (ET; ie, freeze-all cycles), integrating preimplantation genetic screening and contemplating the use of cryopreserved oocytes as a viable resource. Vitrification's impact on clinical treatments is akin to the advent of sperm injection technology in the 1990s on male factor infertility. An appreciable and quantifiable difference was made, with procedural efficacy and global reliability essentially being guaranteed. Yet, there are challenges in the current trends and perspectives in how this technology is and will be optimized in the future. User variation in vitrification products and procedures warrants stricter adherence to quality control measures to enhance specimen biosafety and patient satisfaction, while reducing potential liability concerns. Furthermore, future progress in our understanding of the chemical and cryophysical processes of vitrification will insure the effective cryostorage of reproductive tissues and gametes at a level attained for embryo cryopreservation today.
\end{abstract}

Keywords: vitrification, embryos, oocytes, reproductive tissue, sperm, human

\section{Insights into the pioneering past of vitrification}

The concept and development of kinetic vitrification is credited to Father Basile J Luyet, a Professor of Biology at Saint Louis University. Luyet ${ }^{1}$ reviewed historic research in cryobiology and published summaries of experiments which mostly involved freezing under natural conditions, without the presence of cryoprotective agents (CPAs). ${ }^{2}$ Luyet $^{1}$ showed that supercooled solutions could become so viscous that they solidified without crystallization, forming a transparent glass state, and that this transparent frozen state was equivalent to "vitrification." Furthermore, he determined that although you may vitrify something successfully in the cooling phase, it did not mean you could sustain life, because when you warm it back up it may return to the crystalline state and cause cellular damage. ${ }^{2}$ Later in the 1950s, Gonzales and Luyet $^{3}$ experienced limited success vitrifying chick hearts and neural tissue explants. ${ }^{4}$ Insights into this pioneering history of cryobiology and the early efforts of other investigators have been reviewed..$^{5}$ As for Luyet, he went on to become the founding president of the Society for Cryobiology in 1964.
Correspondence: Mitchel C Schiewe Ovation Fertility, ART Laboratory, 361 Hospital Road, Suite 433, Newport Beach, CA 92663, USA

$\mathrm{Tel}+\mathrm{I} 9496425954$

Fax + I 9496422954

Email mschiewe@ovationfertility.com 
In the late 1970 s and early 1980 s, renewed interests in the underlying concept of cryopreserving living tissue under the metastable solidification of water without ice growth (ie, vitrification) became a fascination of two independent, brilliant-minded postdoctoral fellows in the field of cryobiology. Neither Drs Greg Fahy nor Bill Rall (pre-1985) could have foreseen the tremendous effectiveness that vitrification would have on maintaining the cryoviability of oocytes and embryos. Fahy's applied aspirations focused on the challenges of whole tissue/organ preservation, believing that if the CPA concentration was sufficiently high, the crystallization of water molecules in the extracellular medium could be inhibited completely and become vitrified. ${ }^{6,7}$ Meanwhile, Rall et al ${ }^{8}$ were intrigued with innocuous ice formation inside cells during conventional freeze procedures that accommodated cellular survival. Using cryomicroscopy, it was observed that CPAs substantially increase viscosity of intracellular regions, causing water diffusion to cease and the liquid cytoplasm to form a metastable glass upon rapid cooling. Rall and coworkers ${ }^{10}$ were confident that conventional embryo cryopreservation procedures could be simplified for on-farm use, and possible in-field conservation efforts, without a need for electronic equipment. After years of mutual respect and idea sharing, the scientific union of Fahy and Rall was formalized through the support of Harold Meryman, Scientific Director at the American Red Cross Blood Research Laboratory (Bethesda, MD, USA) in 1983. Under cold room experimental conditions, they successfully vitrified mouse embryos in $1985,{ }^{11}$ as previously reviewed. ${ }^{12}$ In Rall's ${ }^{13}$ efforts to develop an effective procedure working under room temperature conditions, it was determined that propylene glycol was highly toxic at higher concentrations. However, a third-generation vitrification solution (VS3a, a 6.5 M glycerol solution) produced high survival levels and positive pregnancy outcomes in closed one-step $0.25 \mathrm{~mL}$ straws, being comparable to conventional slow freezing of mouse embryos ${ }^{14}$ and sheep blastocysts. ${ }^{15,16}$

By 1990, a new focus on vitrification began, one which emphasized minimizing the potential toxicity of vitrification solutions. ${ }^{17}$ Our understanding of vitrification solutions and their potential toxicity to embryos was enhanced by the efforts of a few insightful pioneers in the field of reproductive cryobiology. ${ }^{18-22}$ Their efforts led to the combined use of mixed permeating CPAs (eg, ethylene glycol [EG], dimethyl sulfoxide [DMSO] and glycerol), as well as non-permeating solutes (eg, sucrose and ficoll) that factored into reducing toxicity potential of individual vitrification solutions.

\section{The integration of vitrification into clinical in vitro fertilization (IVF)}

Nearly a decade passed before vitrification was proposed as a serious technology for improving our ability to cryopreserve human oocytes, cleaved embryos and blastocysts. ${ }^{23-26}$ This interest in clinical vitrification was linked to the formation of unique cryodevices such as the Open Pulled Straw, ${ }^{27,28}$ Cryoloops ${ }^{29-31}$ Cryotops $^{32,33}$ and others, ${ }^{23,24}$ whose thin surrounding film of vitrification solution and direct contact with liquid nitrogen $\left(\mathrm{LN}_{2}\right)$ achieved ultrarapid cooling rates. By the mid-2000s, it was the commercial industry, developing new devices (eg, HSV, Cryotip, Rapid-i and Cryolock) and solutions that propelled vitrification's use into clinical IVF laboratories. By 2010, the benefits of vitrified embryos and oocytes, having virtually no change from their fresh state, were gaining worldwide acceptance. ${ }^{34,35}$ The diversity of issues surrounding the pros and cons of both open and closed device systems has been recently discussed by Vajta et al, ${ }^{36}$ and is briefly mentioned in the following paragraphs. Historically, most clinical users of vitrification systems were misled that the ultrarapid cooling rates attained by the direct exposure of open devices to $\mathrm{LN}_{2}$ were necessary to achieve high survival rates with embryos and oocytes. However, time and experience have proven that slower cooling closed systems vitrify equally well in contrast to other open systems, especially with regard to embryo cryopreservation. ${ }^{26}$ Although the majority of oocyte cryopreservation experience and clinical data support the preferred use of open device systems, there is a need for more published reports and experimentation with closed devices before definitive conclusions are made, as mixed results have been reported..$^{37-43}$

During this time period, the relative importance of warming rates to insuring successful vitrification was proven in a murine experimental model system by Seki and Mazur (the father of modern cryobiology) ${ }^{44-47}$ Using a nonequilibrium, unstable vitrification solution model, they clearly proved that rapid to ultrarapid warming is the key determinant overriding conditions created at any cooling rate. Vitrification warming is a complex process, in that a closed device (eg, standard sealed straw) that achieves intermediate cooling rates $\left(100-2000^{\circ} \mathrm{C} / \mathrm{min}\right)$ performs well with an intermediate warming rate of $\geq 2950^{\circ} \mathrm{C} /$ min, whereas an open system utilizing high cooling rates $\left(>10,000^{\circ} \mathrm{C} / \mathrm{min}\right)$ experiences decreased survival at lower warming rates. Thus, open system devices achieving exceptionally high cooling rates, due to the low thermal mass of their microvolumes, are dependent on equally high warming rates for optimal success. ${ }^{43}$ Using a nonequilibrium 
vitrification system, one should keep in mind that the faster one cools, the smaller the size of the invisible extracellular crystals in solution (ie, heterogeneous nuclei); the smaller the nucleated crystals are the greater their driving force to increase in size upon recrystallization during warming (ie, devitrification). In turn, one must warm more rapidly to combat the injurious effect of recrystallization. ${ }^{43}$ Indeed, vitrification is a highly complex process,${ }^{36}$ whereby a reciprocal interaction exists between the cooling rate required to achieve vitrification of a solution and the concentration of CPA(s)/solutes. ${ }^{48,49}$ Overall, these findings have lent support to the effective development and use of aseptic, closed vitrification device systems (HSV, ${ }^{38,50}$ Vitrisafe, ${ }^{39,43}$ microSecure, ${ }^{40,51}$ SafeSpeed $^{52}$ ), proving that open device systems were not a requirement for successful oocyte and embryo vitrification outcomes. In contrast, only higher volume, closed systems have proven effective to date for the vitrification of reproductive tissue. ${ }^{53,54}$ The key component to optimizing post-warming survival, independent of device used, is to insure that the warming rate is greater than the cooling rate; of which the need for speed is inversely correlated with the concentration of the CPA used. The thermodynamics of cryophysical and chemical relationships has been reviewed ${ }^{55,56}$ and eloquently discussed by Wowk. ${ }^{57}$

Although it took more than 20 years of development, vitrification has transformed the IVF industry, with regard to oocyte cryobanking ${ }^{34,58,59}$ and the justified adoption of freeze-all IVF cycles $^{35}$ in conjunction with blastocyst culture and micromanipulation. As the story continues to unfold, in terms of devices and vitrification solutions, today blastocysts are vitrified with great confidence that their fresh-state viability will be completely sustained. This is particularly true in conjunction with blastocyst biopsy/preimplantation genetic screening (PGS)-single ET applications, ${ }^{60,61}$ where over $99 \%$ survival can be typically achieved, ${ }^{62}$ along with efficient pregnancy success across all age groups following single euploid ET. With embryo and oocyte vitrification being the most significant procedure applied to the assisted reproductive technology (ART) industry since the development of intracytoplasmic sperm injection (ICSI), ${ }^{12}$ it is inconceivable why any IVF program would still be applying conventional slow-freeze (SF) procedures. ${ }^{63}$ In this era of ART where many different vitrification devices and commercial solutions exist, as well as programs transitioning their cryoinventories from slow frozen to vitrified oocytes and embryos, it is important to realize that $1.0 \mathrm{M}$ sucrose is an effective "universal" warming solution. It is not financially feasible, nor practical, to maintain various thawing solutions for slow frozen and vitrified samples. Parmegiani et al's ${ }^{64}$ proposed use of 1.0 M sucrose solution for the step-down dilution of SF embryos is equally effective with vitrified embryos. ${ }^{65}$ By simply halving the sucrose concentration into a three-step, or possibly four-step $(+0.125 \mathrm{M})$, dilution (under ambient temperatures) in decreasing concentrations of sucrose at 2-3 min intervals, prior to final equilibration in isotonic medium, optimum post-thaw survival and viability can be achieved. In fact, in one pilot study in our laboratory, the CPAs in vitrified blastocysts were effectively eluted in $1.0 \mathrm{M}$ sucrose over $5 \mathrm{~min}$ before direct isotonic equilibration. ${ }^{66}$ Granted such an action creates unnecessary osmotic stress on an embryo, it does demonstrate the physiologic functionality of the phospholipid bilayer of blastomere membranes cryopreserved by vitrification. It is not known, however, whether the plasticity of the oolemma would be equally forgiving to sustain the viability of the largest single cell in the human body. Indeed, post-warming dilution protocols do vary considerably (ie, time interval and steps), dependent on cell permeability and the CPAs used, an area that could benefit from more controlled comparative experimentation.

\section{Overcoming variables impeding clinical progress and legal liability}

The commercial development of numerous types of vitrification devices and solutions has facilitated the application of clinical vitrification, but has also created technical inconsistencies between laboratories. Depending on the device and its learning curve, technical variation must be accounted for, as recently discussed ${ }^{67}$ What can be performed to minimize intra- and inter-laboratory procedural variation beyond the essential need for training? Numerous risk factors and safety issues associated with different vitrification methods should be considered (eg, $\mathrm{LN}_{2}$ device handling; device design flaws; shipment concerns and viral cross-contamination of semen, embryos or ova), ${ }^{25,36,40,67-69}$ but are not reviewed in this article. In essence, there are basic quality control (QC) factors warranting implementation to make vitrification a consistent, efficient, reliable and highly effective ART procedure that minimize liability and maximize success. The processes in need of QC considerations include the following: pre-vitrification organization, labeling, cryodilution, aseptic technique and possible aseptic storage, container loading and sealing/protection, reliability and repeatability, warming temperatures and CPA elution and $\mathrm{LN}_{2}$ storage, handling and shipment. An ideal vitrification device and method should allow for a repeatable 
volume of vitrification solution, containing embryo/ova, to be loaded simply in a time-sensitive, reliable, controlled manner, devoid of air bubbles. The goal is to eliminate technical variation, while optimizing $100 \%$ recovery and high survival rates. Recovery rates should not be minimized, as they represent a potential design flaw to a device and create a serious liability risk to the group who ultimately discovers a problem with this issue. ${ }^{67}$ Obviously, training and experience are critical to reducing technical variation and insuring reliable consistent outcomes.

Serious liability issues can arise regarding the reliability of given device systems and poor recovery potential (ie, $>1 \%$ loss rate). When an embryo or egg(s) fails to be recovered, this situation can present serious problems, especially if the sample had been vitrified by another laboratory and/or the receiving laboratory is unfamiliar with a given device? This is especially so if the lost specimen represents the patient's last option. Was the device tapped or jostled pre- or post-vitrification, the specimen accidentally aspirated pre-vitrification or simply not identified post-warming? These are the questions which are ultimately asked and typically remain unresolved. In short, was it technical incompetence pre- or post-vitrification, or was it simply device failure in-between? The latter situation is not helpful for laboratories facing potential legal litigation, and unfortunately case precedence does exist in the US court system. In turn, the emphasis on universal reliability and repeatability must be seriously regarded. The reality is that highly qualified embryologists and experienced laboratories warming vitrified specimens are vulnerable to the procedural QC habits (good and bad) and device choices (open, closed or hybrid systems) used by other ART laboratories and their staff. ${ }^{67}$ Failure to identify eggs can be particularly problematic in devices that do not allow direct visualization of the eggs on or in the device, because they can become highly translucent in 1.0 M sucrose solutions (ie, T1) immediately postwarming/elution. Unfortunately, most published reports simply hide their recovery failures in their otherwise good overall survival rates. This form of data manipulation, however, does not allow the industry to accurately assess the potential QC flaws inherent to certain device systems, nor anticipate possible liability risks. Conversely, vitrified oocyte recovery rates were recently published in a reasonable and informative manner in a randomized controlled trial (RCT) device study, revealing a 2.6\% loss rate using semi-closed CryoTopSC devices compared to the aseptic closed CBS-HSV system $(0 \%) .{ }^{37}$

\section{Current trends and challenges with embryos, gametes and reproductive tissue \\ Blastocyst vitrification}

The development and clinical application of blastocyst vitrification has experienced the greatest success in terms of maintaining the viability of fresh embryos, ${ }^{70}$ being superior to conventional slow freezing. ${ }^{26,71}$ Post-warming, blastocysts tend to appear completely intact, with the occasional appearance of a few necrotic outer trophectodermal cells. In contrast, approximately $25 \%$ of cleaved embryos may have one or two blastomeres degenerate, while the remaining embryo is highly viable. ${ }^{72,73}$ Non-incorporated cells and fragments outside the trophectoderm of blastocysts commonly appear degenerate post-warming. It is very uncommon to observe a completely lysed blastocyst, and care should be taken to culture these embryos as they may have experienced an initial granular transitional phase, but sometimes appear quite normal after a couple hours in culture. Blastocyst reexpansion before ET is desired, but should not be used as a key determinant for viability as some embryos simply require more time to equilibrate. Osmotic responsiveness to sucrose dilutions and the maintenance of membrane integrity/cellular clarity are reliable indicators of post-warming embryo survival. Today, complete blastocyst survival rates routinely exceed $95 \%$, and vitrified ET (VFET) live birth outcomes are routinely equal to or higher than fresh ET success, ${ }^{74}$ likely due to impaired endometrial receptivity in fresh, hyperstimulation cycles. ${ }^{75}$

To promote and insure high blastocyst survival, previtrification blastocoel collapsing (ie, fluid volume reduction) has been adopted, as reviewed by Liebermann and Conaghan. ${ }^{76}$ The artificial collapsing of blastocysts prior to vitrification has been proven to be effective using a variety of methods, ${ }^{77,78}$ with trophectoderm laser ablation being the simplest approach, sacrificing a single cell for the greater good of the whole embryo. Hatched blastocyst and fully expanded, zona intact blastocysts certainly have the greatest need for volume reduction before vitrification to enhance post-warming viability. However, it appears that this need to manually collapse a blastocyst is dependent on the type and concentration of the CPAs used. Most commercial vitrification solutions contain a mixture of DMSO and EG which possess high permeation coefficients, in contrast to glycerol, thus achieving osmotic equilibration and possible blastocoel reexpansion in a shorter interval. Therefore, it is not surprising that the use of an alternative glycerol-EG-based solution (Innovative Cryo Enterprises (ICE), Linden, NJ, USA) in our 
laboratory, ${ }^{40,62}$ and others, ${ }^{79}$ does not require artificial collapsing to achieve high post-warming survival, as the slower permeating glycerol effectively reduces water influx before cooling. Using this higher concentrated glycerol-based solution, devoid of DMSO, in a highly effective noncommercial aseptic, closed system, ${ }^{51}$ has revealed that high pregnancy outcomes can routinely occur across all age groups without the pre-vitrification application of blastocoel collapsing. ${ }^{40,62}$

It has become increasingly evident, since first proposed by Grifo et al, ${ }^{80}$ that the transfer of a single euploid vitrified/ warmed blastocyst, independent of age, is the most efficient way to achieve a high implantation rate and live birth rate (IR/LBR), as clearly confirmed in other recent reports. ${ }^{35,62}$ Furthermore, although there is no difference in IR/LBR using either day 5 or day 6 euploid blastocysts, the miscarriage rate tends to be higher using a day 6 early to full blastocysts (grade $\leq 3$ ) or embryos with B-quality trophectoderm. ${ }^{81}$ Whether PGS is applied, or not, it is routinely accepted that blastocyst viability is not compromised by vitrification, nor micromanipulation, and that delayed ET cycles using the warmed blastocyst can be advantageous. ${ }^{62,80,82}$ To date, the possible epigenetic effects of embryonic vitrification solution exposures have not been elucidated; however, it has been shown that aneuploidy rates do not increase in blastocysts vitrified as oocytes. ${ }^{83,84}$ Furthermore, it is doubtful whether there is a genetic consequence to vitrifying blastocysts considering their high post-warming IRs and live birth success. Based on the exceptional reliability of embryo vitrification and normal neonatal outcomes, ${ }^{85}$ there is a growing trend in the IVF industry replacing fresh ET with freeze-all cycles, especially in older patient populations ( $>37$ years old) and PGS-tested patients, as the prior fear of the best quality embryo may not survive post thaw no longer exists. Today, "freeze-all" VFET can efficiently achieve IRs in excess of $65 \%$ (up to $84 \%$ ), independent of age, after single euploid ET (Table 1). While fresh ET success rates have remained relatively dormant between 2010 and 2015 (eg, donor egg LBR: 55.8-56.8\% LBR/ET), frozen ET success has steadily increased from $38.4 \%$ to $46.6 \%$ total LBRs transferring fewer embryos/ET ${ }^{86}$ In turn, blastocyst vitrification in conjunction with PGS has facilitated improved embryo utilization rates aimed at more efficiently creating healthy singleton births (<31.9-36.5\% from 2010 to 2015 ).

\section{Oocyte vitrification}

Breakthrough efforts in early oocyte slow freezing success integrated ICSI to reliably achieve fertilization and blastocyst development, ${ }^{87}$ and subsequently healthy live births. ${ }^{88-91}$ However, a couple of years later, early success in vitrifying and warming human oocytes ${ }^{92-94}$ transformed this reproductive practice into a highly efficient freeze preservation method over the past decade. ${ }^{34,58,59}$ Upon verifying the normal health and well-being of over 900 babies produced from embryos derived from slow-frozen and vitrified oocytes, ${ }^{95,96}$ coupled with consistently high survival (>85\%) and good fertilization rates $(>70 \%)$ attained with vitrification, a Practice Committee of the American Society for Reproductive Medicine (ASRM) reclassified oocyte cryopreservation technology as "nonex-

Table I Select information from the national summary of ART statistics by the CDC reviewing the frozen ET results of non-donor egg cycles

\begin{tabular}{|c|c|c|c|c|c|}
\hline \multirow[t]{2}{*}{ Frozen embryos: autologous cycles } & \multicolumn{5}{|c|}{ Age groups (years) } \\
\hline & $<35$ & $35-37$ & $38-40$ & $41-42$ & $43-44$ \\
\hline \multicolumn{6}{|l|}{ SCCRM: $2014 / 2015$} \\
\hline No. of cycles & $82 / 93$ & $75 / 70$ & $72 / 68$ & $27 / 29$ & $9 / 11$ \\
\hline Mean \#ET & I.I/I.0 & $1.2 / 1.1$ & $1.2 / 1.1$ & I.I/I.I & $1.4 / 1.0$ \\
\hline$\%$ IR & 77.9/7I.3 & $61.0 / 69.4$ & $60.0 / 71.4$ & $84.0 / 64.3$ & $6 / \mid 3 / 6 / 11$ \\
\hline \%LBR/ET & $73.1 / 68.8$ & $66.2 / 65.7$ & $55.0 / 69.1$ & $69.6 / 58.6$ & $5 / 9 / 6 / 11$ \\
\hline \%Healthy single/ET & $56.4 / 61.3 *$ & $56.3 / 55.7$ & $48.3 / 54.4$ & $69.6 * / 48.3$ & $4 / 9 / 6 / 11$ \\
\hline \multicolumn{6}{|l|}{ Mean CDC 2014} \\
\hline No. of cycles & 26,182 & 13,539 & 10,078 & 3,792 & $\mathrm{I}, 8 \mid \mathrm{I}$ \\
\hline Mean \#ET & 1.6 & 1.5 & 1.6 & 1.7 & $\mathrm{I} .8$ \\
\hline$\% \mathrm{IR}$ & 43.7 & 40.8 & 35.2 & 28.4 & 19.9 \\
\hline \%LBR/ET & 46.6 & 44.0 & 38.3 & 32.1 & 23.1 \\
\hline \%Healthy single/ET & 30.7 & 30.6 & 27.1 & 23.3 & 16.8 \\
\hline
\end{tabular}

Notes: The data contrast the SCCRM clinic in 2014 and 2015 to the national average in 20I4. SCCRM and its affiliated Ovation Fertility Laboratory have strived to optimize the quality of patient care by implementing a clinical practice of predominantly PGS/vitrification-all cycles. In turn, the use of single euploid ET maximizes implantation and healthy singleton live birth successes. *The SCCRM clinic achieved some of the highest healthy singleton LBR in the USA in 2015 (ie, healthy single: normal birthweight term singleton). Data from Centers for Disease Control and Prevention. Assisted Reproductive Technology Surveillance, National Summary Reports 20I0-20I5. ${ }^{86}$

Abbreviations: ART, assisted reproductive technology; CDC, Center for Disease Control; ET, embryo transfer; IR, implantation rate; LBR, live birth rate; PGS, preimplantation genetic screening; SCCRM, Southern California Center for Reproductive Medicine. 


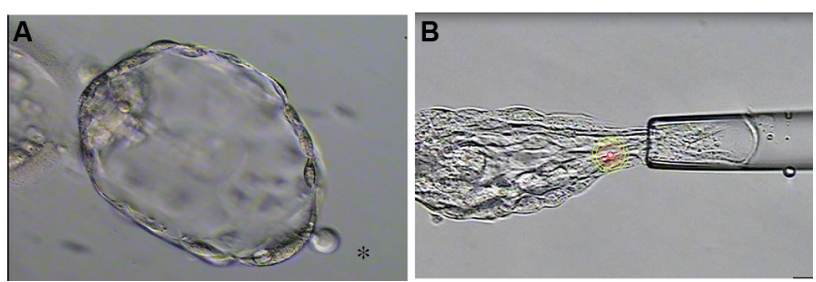

Figure I Laser manipulation of human embryos.

Notes: (A) The hatched blastocyst possessing a single nonviable, unincorporated trophectodermal cell (*) following pre-vitrification laser-mediated blastocoel collapse and post-warming in vitro culture. (B) Routine biopsying of trophectodermal cells via laser-assisted, micro-aspiration has confirmed the biosafety of infrared diode lasers and further proven the resiliency of embryos to micromanipulation and subsequent cryopreservation.

perimental" in 2013. ${ }^{97}$ It is important to realize that the intent of this decision was to facilitate the application of this freeze preservation practice for female cancer patients, without the obstacles of informed research consent. A major determinant in lifting the "experimental" classification was the consistent evidence revealing that genetic anomalies occur at a rate of $<2 \%$ in babies derived from vitrified oocytes, being no different than fresh oocytes. ${ }^{98}$

There is no doubt that the most important application for oocyte cryopreservation is to provide a "fertility preservation" option for women undergoing potential sterilizing medical treatments, or medical uncertainty during their remaining fertile years. As medical care continues to improve for women faced with life-threatening diagnoses, oocyte vitrification is indeed the best option to preserve a woman's future fertility if unmarried or unwilling to use donor sperm, knowing that blastocyst vitrification is a more well proven and reliable cryopreservation option..$^{99}$ Another important application is in emergency IVF cycle situations where upon on the day of oocyte retrieval there is no sperm present in a testicular biopsy or due to ejaculatory failure. Despite advanced planning, clinical laboratories worldwide are repetitively faced with this latter issue, but now have an effective solution to rescue an IVF cycle with vitrification.

The commercial banking and marketing of donor oocytes is probably the fastest growing and largest application of oocyte cryopreservation technology. Details on this growing industry have been reviewed by others. ${ }^{100,101}$ Suffice it to say, the majority of publications boosting oocyte cryopreservation technologies as being comparable to the use of fresh oocytes are typically associated with egg-banking affiliated professionals. Granted, there have been RCTs supporting the efficacy of vitrified donor and autologous eggs. ${ }^{34,102} \mathrm{Cer}-$ tainly, oocyte cryopreservation has proven to be a viable and effective clinical option. ${ }^{59}$ For example, in a recent webinar presentation, $\mathrm{Nagy}^{103}$ reported his experience at My Egg Bank (MEB) in the USA with 21,462 warmed eggs having an $88 \% / 78 \%$ survival and fertilization rate, respectively, with an equally impressive $52 \%$ clinical pregnancy rate using vitrified donor eggs. Although fresh donor egg rates in the USA typically attain an average $55 \%$ live births, many top ART programs are able to routinely attain $65-85 \%$ LBRs. That level of success has yet to be reported using vitrified oocytes. In contrast, commercial egg banks repeatedly report sub-50\% LBRs, as do published IVF programs..$^{34,58,104,105}$ Excluding the occasional outlier publishing an impressive data set, ${ }^{98,106}$ the average clinical practice is not publishing their variable experience with oocyte cryopreservation that fails to attain the levels reported by commercial propaganda. There is, however, general agreement that blastocysts derived from vitrified oocytes are the same as fresh, ${ }^{99,107,108}$ or from vitrified blastocysts for that matter. To optimize pregnancy and live birth success, it is generally accepted that if $>8$ oocytes are available, it is more favorable to culture and transfer at the blastocyst stage. ${ }^{109}$ Yet, warming more oocytes per cycle does not necessarily insure that more blastocysts may be produced from a given batch source. Overall, the disparity observed in everyday laboratory practice, especially in terms of developmental competence, indicates that there is more to learn about oocyte cryopreservation, specifically how egg quality and development are influenced by factors such as hormonal stimulation, cytoplasmic maturation, organelle functionality and membrane permeability. ${ }^{110}$ Furthermore, more RCTs are needed to compare open and closed vitrification devices, cooling rates and warming rates, as well as unstable and metastable non-equilibration solutions, if we are to truly optimize the reliability and repeatability of oocyte vitrification in the future. ${ }^{37,39}$

The difficulties associated with improving oocyte cryopreservation are related to understanding the special structure and sensitivity of this large single cell, ${ }^{111}$ and considering the overall physiology of oocytes. ${ }^{12}$ We may still need to evaluate the varying exposure time and concentration of the $\mathrm{CPA}(\mathrm{s})$ and the equilibrium/maturation interval pre and post-warming, while still inhibiting extra- and intracellular ice formation in conjunction with minimizing potential cytotoxicity, to optimize the viability and developmental capacity of embryos. Several studies evaluating the effect of vitrification and slow freezing on the meiotic spindle integrity and chromosome alignment revealed that less damage occurred in vitrified oocytes, ${ }^{113,114}$ and that spindle recovery was more rapid following vitrification (1-2 $\mathrm{h}$ post-warming) compared to slow freezing. ${ }^{115}$ However, other studies evaluating vitrified-warmed oocytes suggested that chromosomal alignment may be partly compromised. ${ }^{115,116}$ Furthermore, 
other biological characteristics of human oocytes that might confer susceptibility to damage during the cryopreservation procedure include: 1 ) the low permeability coefficient of the oolemma, which makes the penetration of cryoprotectant substances more difficult, and their intracytoplasmic lipids which make them more sensitive to freezing than embryos; ${ }^{117} 2$ ) precocious oocyte activation induced by exposure to cryoprotectants which may disturb future development; ${ }^{12,114}$ 3) loss of high mitochondrial polarity associated with a significantly reduced capacity to upregulate the levels of intracellular free calcium after thawing ${ }^{118}$ and 4) microvacuolization in the ooplasm and ultrastructural alterations in specific oocyte microdomains have been linked to a reduced developmental potential of mature cryopreserved oocytes. ${ }^{119}$ Furthermore, there remains a need to understand more about the level of gene regulation and energetics that could be responsible for decreasing the developmental potential of the vitrified cytoplasm.

The commercialization of oocyte cryopreservation was an unanticipated and somewhat disturbing trend as a direct by-product of ASRM's decision to qualify this technology as nonexperimental. This was not so much from the donor egg bank marketing perspective, but more in terms of the clinical promotion of elective fertility preservation of women (of all age groups) through egg banking. Clearly, there are age limits that should be considered, which influence the effectiveness of future fertility efforts. ${ }^{108,120}$ Yet, the biggest problem has lied in every IVF clinic in the world suddenly considering themselves as qualified authorities on oocyte cryopreservation, capable of applying a textbook recipe without experience or any proven pregnancy success of their own, just because the technology was deemed "nonexperimental." More than 5 years later, oocyte vitrification practices have yet to be optimized nor their developmental competence issues fully understood. Granted, when it works well and yields good quality blastocysts, one can anticipate excellent pregnancy outcomes, similar to fresh eggs. ${ }^{59,99,108}$ More often, however, the average laboratory frequently observes slower and lower blastocyst development. More importantly, more than $10 \%$ of the vitrified egg batches will likely fail to yield a transferrable embryo. This phenomenon was recently documented in a 137 and 368 autologous egg banking cycles in Spain and the USA, respectively, with $12-21.2 \%$ of the fertilized oocyte warming cycle failing to yield an embryo for transfer. ${ }^{104,121}$ It is to be kept in mind that survival rates and normal fertilization events tend to be consistent (75-95\% and 65-85\%, respectively), with survival failure being a rare event $(<2 \%) .{ }^{105}$ Perhaps the greatest concern then is that naive, innocent female consumers (ie, perspective patients) are being misinformed about their risks, by financially motivated programs, that the freeze preservation of their potential fertility based on today's technology does not guarantee that a transferrable embryo will even result, let alone potentially create a healthy baby. As there is no stopping the elective fertility preservation movement, the latter unanticipated result begs us to redirect the question, does this technology truly not require continued experimentation to improve its overall efficacy, reliability and long-term effectiveness? A recent series of reciprocal nuclear transplantation experiments involving fresh and vitrified sheep oocytes has clearly confirmed that the vitrified cytoplasm of oocytes is the possible source of a zygotes' developmental incompetence, as opposed to chromatin defects in the meiotic spindle. ${ }^{122}$ Due to the high costs, resource availability and ethical considerations of generating human oocytes for experimentation, research progress will undoubtedly be slow, but necessary.

\section{Human ovarian tissue vitrification}

Gosden et al ${ }^{123}$ were the first to explore the realm of ovarian tissue cryopreservation using slow freezing methods with sheep ovaries. Similar freeze preservation success has subsequently been achieved in the human beings using both SF and vitrification methods. ${ }^{53,124-127}$ Comparative vitrification solution trials have been initiated to identify optimal solutions for ovarian tissue freeze preservation. ${ }^{54,128}$ Promising vitrification results have also been attained in a Macaque monkey model using a metastable solution composed of $25 \%$ EG, 25\% glycerol and polymers in a closed system device. ${ }^{129}$ Applying a two-step warming process, the latter investigators efficiently preserved the follicular morphology and stromal tissue of the ovarian cortex. In addition, there have been promising developments in the cryopreservation of whole organs (eg, kidneys) by perfusion with metastable vitrification solutions ${ }^{130}$ that could have direct application with ovaries, as the effective external permeation of CPAs is concentration and rate dependent relative to tissue type and mass. Perfusion offers a mechanism to uniformly distribute CPAs throughout the tissue bed. Sheep ovaries have been successfully perfused for $10 \mathrm{~min}$ with a $10 \%$ DMSO solution followed by SF and thawed at $68^{\circ} \mathrm{C}$ for $20 \mathrm{~s}$ and then $37^{\circ} \mathrm{C}$ for 4 min. ${ }^{131}$ Upon successful transplantation, these slow frozen perfused ovaries maintained physiological functionality after 6 years in vivo. ${ }^{132}$ Successful perfusion and slow freezing of human ovaries has also been reported. ${ }^{133}$ Ovarian tissue in humans, however, has generally been slowly cryopreserved as cortical biopsies or strips with proven in vivo transplantation success, ${ }^{134}$ yet whole ovary perfusion and 
vitrification are promising technologies for future clinical application. ${ }^{135,136}$ Today, ovarian tissue cryopreservation and transplantation are still regarded as experimental. ${ }^{137}$ Regardless, it is a viable option for patients who require immediate gonadotoxic medical treatment and is the only option available for prepubertal girls. ${ }^{124,137,138}$ Overall, there is agreement in the fertility community that this technology should not be offered to patients with benign conditions or for the purpose of delaying childbearing, as embryo and oocyte vitrification are more efficient and effective approaches.

\section{Human sperm vitrification}

In lieu of Luyet's original assertions, it is reasonable to believe that small cells with little intracellular water, such as sperm, can survive kinetic vitrification in the absence of permeating CPAs under rapid cooling conditions. Indeed, that has been the experience of Evgenia and Vladimir Isachenko and their colleagues in Cologne, Germany, whom first reported the successful cryopreservation of human sperm without cryoprotectants in 2002. ${ }^{139}$ Using a $0.5 \mathrm{M}$ sucrose vitrification solution, these investigators developed an effective kinetic vitrification system. ${ }^{140-144}$ These efforts were particularly well suited for the cryopreservation of low numbers of sperm isolated in microvolume suspensions contained on or in different devices (eg, Cryoloop, grids/mesh, Cryotops, cut-straw microdrops and capillary tubes). ${ }^{140,143,145,146}$ It was proven that sperm functionality, as measured by acrosomal integrity, mitochondrial activity, plasma membrane function, DNA fragmentation, motility and fertilizability, was similar to or better than conventional slow freezing. ${ }^{141,142,144,147-149}$ Clinical efforts have further shown that vitrification of sperm in higher volumes (up to $0.5 \mathrm{~mL}$ ) can be a practical and effective treatment achieving pregnancies and live births by IVF and intrauterine insemination (IUI) procedures. ${ }^{141,142,145,147,150-154}$ Although kinetic sperm vitrification has been proven effective for over 15 years, ${ }^{5,147}$ it has not been met with the same large-scale acceptance and industry application afforded to eggs and embryos. However, as experimentation continues and more users become familiar with this technology, a trend away from traditional sperm freezing in the presence of toxic CPAs could well occur overtime. It is worth adding that although testicular tissue vitrification has been successfully applied, ${ }^{155}$ the current technology of rapid freezing of whole biopsy tissue (ie, seminiferous tubular masses) has proven to be effective in clinical application. ${ }^{156}$ In turn, it is unlikely that the vitrification of sperm and testicular tissue will ever gain the industry-wide acceptance and popularity granted to embryos, oocytes and perhaps ovarian tissue in the future.

\section{The future is guaranteed}

Today, the advantages of vitrification appear to significantly outweigh any potential pitfalls, if one can clearly assess any. Under well-controlled vitrification conditions, there should be no damaging ice crystal formation to cause osmotic, physical or physiological disruption of cellular function. Procedures are performed simply, reliably and rapidly with relatively brief exposures to concentrated, biosafe CPAs, without the cost of electronic equipment and maintenance of a programmable freezer. ${ }^{24}$

Vitrification has made a lasting impact in the IVF industry over the past decade, literally changing the way reproductive endocrinologists and biologists approach infertility treatment. It has been successfully applied to oocytes and embryos by laboratories using both open and closed systems, as well as unstable or metastable nonequilibrium vitrification solutions. The relationship between device type and solution choice is complicated. Although some very effective DMSO/glycol and non-DMSO solutions have been developed, there is significant variation in the efficacy of their application depending on the vitrification method applied and the experience of the operator, commonly referred to as "technical signature." 79

As with all ART procedures, there is always room for improvement in their application and outcomes. Steady advancements in reproductive tissue and oocyte vitrification will likely require continued experimentation to further understand membrane functionality, the role of extracellular stabilizing additives (eg, hyaluronate, hydrocellulose and butylated hydroxytoluene) and ice blocking agents (eg, polyvinyl alcohol polymer), organelle functionality and gene expression, cryoprotectant interactions and possible toxicities. Furthermore, quality management improvements aimed to reduce technical variation will all prove critical to optimizing vitrification in the future. Ideally, vitrification systems will be mindful of QC considerations to enhance procedural consistency and repeatability, with a common goal to eliminate technical signature by reducing intra- and interlaboratory variation. Indeed, the future of cellular viability is infinite in the wondrous world of metastable glass formation and the controlled elimination of recrystallization events, while maintaining normal physiological processes.

\section{Disclosure}

The authors report no conflicts of interest in this work.

\section{References}

1. Luyet BE. The vitrification of organic colloids and of protoplasm. Biodynamica. 1937;1:1-14. 
2. Luyet BJ, Gehenio PM. In: Luyet BJ, editor. Life and Death at Low Temperatures. 1st ed. Normandy, MI: Biodynamica; 1940:1-328.

3. Gonzales F, Luyet B. Resumption of heart-beat in chick embryo frozen in liquid nitrogen. Biodynamica. 1950;7(126-128):1-5.

4. Luyet B, Gonzales F. Growth of nerve tissue after freezing in liquid nitrogen. Biodynamica. 1953;7(141-144):171-174.

5. Katkov II, Bolyukh VF, Chernetsov OA, et al. Kinetic vitrification of spermatozoa of vertebrates: what can we learn from nature? In: Katkov II, editor. Frontiers in Cryobiology. Croatia: InTech; 2012:3-40.

6. Fahy GM, MacFarlane DR, Angell CA, Meryman HT. Vitrification as an approach to cryopreservation. Cryobiology. 1984;21(4):407-426.

7. Fahy GM, Wowk B, Pagotan R, et al. Physical and biological aspects of renal vitrification. Organogenesis. 2009;5(3):167-175.

8. Rall WF, Reid DS, Farrant J. Innocuous biological freezing and warming. Nature. 1981;286(5772):511-514.

9. Rall WF, Reid DS, Polge C. Analysis of slow-warming injury of mouse embryos by cryomicroscopical and physiochemical methods. Cryobiology. 1984;21(1):106-121.

10. Rall WF, Schiewe MC, Bush M, Wildt DE. Cryopreservation of oocytes and embryos collected from wildlife species. Cryobiology. 1989;26:562-563.

11. Rall WF, Fahy GM. Ice-free cryopreservation of mouse embryos at -196 degrees C by vitrification. Nature. 1985;313:573-575.

12. Schiewe MC. The historic development and incorporation of four assisted reproductive technologies shaping today's IVF industry. JFIV Reprod Med Genet. 2016;4(2):173-181.

13. Rall WF. Factors affecting the survival of mouse embryos cryopreserved by vitrification. Cryobiology. 1987;24(5):387-402.

14. Rall WF, Wood MJ, Kirby C, Whittingham DG. Development of mouse embryos cryopreserved by vitrification. J Reprod Fertil. 1987;80(2):499-504.

15. Schiewe MC. Comparative Estrous Synchronization, Ovarian Stimulation, Luteal Function and Embryo Cryopreservation of Domestic Sheep and Nondomestic Species [dissertation]. Bethesda, MD: Uniformed Services University of the Health Sciences (USUHS); 1989.

16. Schiewe MC, Rall WF, Stuart LD, Wildt DE. Ovine embryo cryopreservation: analysis of cryoprotectant, cooling rate and in situ straw dilution using conventional freezing or vitrification. Theriogenology. 1991;36:279-293.

17. Kasai M, Komi JH, Takakamo A, Tsudera H, Sakurai T, Machida T. A simple method for mouse embryo cryopreservation in a low toxicity vitrification solution, without appreciable loss of viability. J Reprod Fertil. 1990;89(1):91-97.

18. Shaw JM, Diotallevi L, Trounson AO. A simple rapid 4.5M dimethyl sulphoxide freezing technique for the cryopreservation of one-cell to blastocyst stage preimplantation mouse embryos. Reprod Fertil Dev. 1991;3(5):621-626.

19. Shaw JM, Kuleshova LL, MacFarlane DR, Trounson AO. Vitrification properties of solutions of ethylene glycol in saline containing PVP, Ficoll, or dextran. Cryobiology. 1997;35(3):219-229.

20. Ali J, Shelton JN. Design of vitrification solutions for the cryopreservation of embryos. J Reprod Fertil. 1993;99(2):471-477.

21. Kasai M, Nishimori M, Zhu SE, Sakurai T, Machida T. Survival of mouse morulae vitrified in an ethylene glycol-based solution after exposure to the solution at various temperatures. Biol Reprod. 1992;47(6):1134-1139.

22. Mukaida T, Wada S, Takahashi K, Pedro PB, An TZ, Kasai M. Vitrification of human embryos based on the assessment of suitable conditions for 8-cell mouse embryos. Hum Reprod. 1998;13(10): 2874-2879.

23. Liebermann J, Dietl J, Vanderzwalmen P, Tucker MJ. Recent developments in human oocyte, embryo and blastocyst vitrification: where are we now? Reprod Biomed Online. 2003;7(6):623-633.

24. Vajta G, Nagy ZP. Are programmable freezers still needed in the embryo laboratory? Review on vitrification. Reprod Biomed Online. 2006;12(6):779-796.
25. Vajta G, Nagy ZP, Cobo A, Conceicao J, Yovich J. Vitrification in assisted reproduction: myths, mistakes, disbeliefs and confusion. Reprod Biomed Online. 2009;19(suppl 3):1-7.

26. Edgar DH, Gook DA. A critical appraisal of cryopreservation (slow cooling versus vitrification) of human oocytes and embryos. Hum Reprod Update. 2012;16:536-554.

27. Vajta G, Lewis IM, Kuwayama M, et al. Sterile application of the open pulled straw (OPS) vitrification method. Cryo Letters. 1998;19:389-392.

28. Vajta G, Holm P, Kuwayama M, et al. Open Pulled Straw (OPS) vitrification: a new way to reduce cryoinjuries of bovine ova and embryos. Mol Reprod Dev. 1998;51(1):53-58.

29. Lane M, Bavister BD, Lyons EA, Forest KT. Containerless vitrification of mammalian oocytes and embryos. Nat Biotechnol. 1999;17(12):1234-1236.

30. Lane M, Schoolcraft WB, Gardner DK. Vitrification of mouse and human blastocysts using a novel cryoloop container-less technique. Fertil Steril. 1999;72(6):1073-1078.

31. Mukaida T, Nakamura S, Tomiyama T, et al. Vitrification of human blastocysts using cryoloops: clinical outcome of 223 cycles. Hum Reprod. 2003;18(2):384-391.

32. Katayama KP, Stehlik J, Kuwayama M, et al. High survival rate of vitrified human oocytes results in clinical pregnancy. Fertil Steril. 2003;80(1):223-224

33. Kuwayama M. Highly efficient vitrification for cryopreservation of human oocytes and embryos: the cryotop method. Theriogenology. 2007;67(1):73-80.

34. Cobo A, Meseguer M, Remohí J, Pellicer A. Use of cryo-banked oocytes in an ovum donation programme: a prospective, randomized, controlled, clinical trial. Hum Reprod. 2010;25(9):2239-2246.

35. Zhu D, Zhang J, Cao S, et al. . Vitrified-warmed blastocyst transfer cycles yield higher pregnancy and implantation rats compared with fresh blastocyst transfer cycles-time for a new embryo transfer strategy? Fertil Steril. 2011;95:1691-1695.

36. Vajta G, Rienzi L, Ubaldi FM. Open versus closed systems for vitrification of human oocytes and embryos. Reprod Biomed Online. 2015;30(4):325-333.

37. De Munck N, Santos-Ribeiro S, Stoop D, Van de Velde H, Verheyen G. Open versus closed oocyte vitrification in an oocyte donation programme: a prospective randomized sibling oocyte study. Hum Reprod. 2016;31(2):377-384.

38. Stoop D, De Munck N, Jansen E, et al. Clinical validation of a closed vitrification system in an oocyte-donation programme. Reprod Biomed Online. 2011;24(2):180-185.

39. Panagiotidis Y, Vanderzwalmen P, Prapas N, et al. Open versus closed vitrification of blastocysts from an oocyte-donation programme: a prospective randomized study. Reprod Biomed Online. 2013;26(5):470-476.

40. Schiewe MC, Zozula S, Anderson RE, Fahy GM. Validation of microSecure vitrification ( $\mu \mathrm{S}-\mathrm{VTF})$ for the effective cryopreservation of human embryos and oocytes. Cryobiology. 2015;71(2): 264-272.

41. De Munck N, Verheyen G, Van Landuyt L, Stoop D, Van de Velde H. Survival and post-warming in vitro competence of human oocytes after high security closed system vitrification. J Assist Reprod Genet. 2013;30(3):361-369.

42. Paffoni A, Guarneri C, Ferrari S, et al. Effects of two vitrification protocols on the developmental potential of human mature oocytes. Reprod Biomed Online. 2011;22(3):292-298.

43. Papatheodorou A, Vanderzwalmen P, Panagiotidis Y, et al. Open versus closed oocyte vitrification system: a prospective randomized sibling-oocyte study. Reprod Biomed Online. 2013;26(6): 595-602.

44. Mazur P, Seki S. Survival of mouse oocytes after being cooled in a vitrification solution to $-196^{\circ} \mathrm{C}$ at $95^{\circ} \mathrm{C}$ to $70,000^{\circ} \mathrm{C} / \mathrm{min}$ and warmed at $610^{\circ} \mathrm{C}$ to $118,000^{\circ} \mathrm{C} / \mathrm{min}$ : a new paradigm for cryopreservation by vitrification. Cryobiology. 2011;62:1-7. 
45. Seki S, Mazur P. Effect of warming rate on the survival of vitrified mouse oocytes and on the recrystallization of intracellular ice. Biol Reprod. 2008;79(4):727-737.

46. Seki S, Mazur P. The dominance of warming rate over cooling rate in the survival of mouse oocytes subjected to a vitrification procedure. Cryobiology. 2009;59(1):75-82.

47. Seki S, Mazur P. Ultra-rapid warming yields high survival of mouse oocytes cooled to $-196^{\circ} \mathrm{C}$ in dilutions of a standard vitrification solution. PLoS One. 2012; 7:e36058.

48. Fahy GM. Biological effects of vitrification and devitrification. In: Pegg DM, Karow AM Jr, editors. The Biophysics of Organ Cryopreservation. New York: Plenum Press; 1987:269-293.

49. Boutron P, Mehl P. Theoretical prediction of devitrification tendency: determination of critical warming rates without using finite expansions. Cryobiology. 1990;27(4):359-377.

50. Van Landuyt L, Stoop D, Verheyen G, et al. Outcome of closed blastocyst vitrification in relation to blastocyst quality: evaluation of 759 warming cycles in a single-embryo transfer policy. Hum Reprod. 2011;26(3):527-534.

51. Schiewe MC. MicroSecure vitrification for oocytes and embryos: optimum simplicity, security cost and effectiveness combining FDAapproved products. J Clin Embryol. 2010;13:33-51.

52. Gallardo M, Hebles M, Migueles B, et al. Thermal and clinical performance of a closed device designed for human oocyte vitrification based on the optimization of the warming rate. Cryobiology. 2016;73(1):40-46.

53. Isachenko V, Isachenko E, Weiss JM. Human ovarian tissue: vitrification versus convention freezing. Hum Reprod. 2009;24(7):1767-1768.

54. Amorium CA, David A, Van Langendoncki A, et al. Vitrification of human ovarian tissue: effect of different solutions and procedures. Fertil Steril. 2011;98:1291-1298.

55. Fahy GM. Overview of biological vitrification. In: Tucker MJ, Liebermann L, editors. Vitrification in Assisted Reproduction. 2nd ed. Boca Raton: CRC Press; 2015:1-22.

56. Wowk B. Thermodynamic aspects of vitrification. Cryobiology. 2010;60(1):11-22.

57. Wowk B. Metastable vitrification of cryoprotective solutions. Proceedings of the 50th Ann Mtg for Society for Cryobiol. You Tube Video "Cryo2013"; 2013.

58. Nagy ZP, Chang CC, Shapiro DB, et al. Clinical evaluation of the efficiency of an oocyte donation program using egg cryo-banking. Fertil Steril. 2009;92(2):520-526.

59. Goldman KN, Noyes NL, Knopman JM, McCaffrey C, Grifo JA. Oocyte efficiency: does live birth rate differ when analyzing cryopreserved and fresh oocytes on a per-oocyte basis? Fertil Steril. 2013;100(3):712-717.

60. Scott Jr RT, Upham KM, Forman EJ, et al. Blastocyst biopsy with comprehensive chromosome screening and fresh embryo transfer significantly increases in vitro fertilization implantation and delivery rates: a randomized controlled trial. Fertil Steril. 2013;100: 697-703.

61. Wells D, Kaur K, Rico A, et al. Clinical utilization of a rapid low-pass whole-genome sequencing technique for the diagnosis of aneuploidy in human embryos prior to implantation. J Med Genet. 2014;51: 553-562.

62. Whitney JB, Anderson RE, Schiewe MC. Single center validation of routine blastocyst biopsy implementation. J Assist Reprod Genet. 2016;33(11):1507-1513.

63. Reinzi L, Garcia C, Maggiulli R, et al. Oocyte, embryo and blastocyst cryopreservation in ART: systematic review and meta-analysis comparing slow-freezing versus vitrification to produce evidence for the development of global guidance. Hum Reprod Update. 2017;23(2): 139-155.

64. Parmegiani L, Tatone C, Cognigni GE, et al. Rapid warming increases survival of slow-frozen sibling oocytes: a step towards a single warming procedure irrespective of the freezing protocol? Reprod Biomed Online. 2014;28(5):614-623.
65. Lopez J, Zech NH, Vanderzwalmen P. Successful vitrification in a closed carrier device of blastocysts originating from infertile patients, egg donors, or in vitro maturation. Fertil Mag. 2009;11:38-409.

66. Zozula S, Zwerling M, Whitney J, et al. MicroSecure vitrification ( $\mu$ SVTF): evaluation of thaw intervals for human blastocysts. Proceedings $A A B / C R B$ Conference. 2012:31-32.

67. Schiewe MC. Quality control factors influencing the successful and reliable implementation of oocyte and embryo vitrification. In: MarcoJiménez F, Akdemir H, editors. Cryopreservation in Eukaryotes. Rijeka, Croatia: InTech; doi 10.5772/65332.

68. Kuwayama M, Vajta G, Ieda S, Kato O. Comparison of open and closed methods for vitrification of human embryos and the elimination of potential contamination. Reprod Biomed Online. 2005;11(5):608-614.

69. Schiewe MC, Zozula S, Nugent N, et al. Modified microSecure vitrification: a safe, simple and highly effective cryopreservation procedure for human blastocysts. J Vis Exp. 2017;121:e54871.

70. Ebner T, Vanderzwalmen P, Shebi O, et al. Morphology of vitrified/ warmed day-5 embryos predicts rates of implantation, pregnancy and live birth. Reprod Biomed Online. 2009;19(1):72-78.

71. Li Z, Wang YA, Ledger W, et al. Clinical outcomes following cryopreservation of blastocysts by vitrification or slow-freezing: a population-based cohort study. Hum Reprod. 2014;29(12):2794-2801.

72. Balaban B, Urman B, Ata B, et al. A randomized controlled study of human day 3 embryo cryopreservation by slow freezing or vitrification: vitrification is associated with higher survival, metabolism and blastocyst formation. Hum Reprod. 2008;23(9):1976-1982.

73. Van Landuyt L, Van de Velde H, De Vos A, et al. Influence of cell loss after vitrification or slow-freezing on further in vitro development and implantation of human day 3 embryos. Hum Reprod. 2013;28(11):2943-2949.

74. Roy TK, Bradley CK, Bowman MC, McArthur SJ. Single-embryo transfer of vitrified-warmed blastocysts yields equivalent live birth rates and improved neonatal outcomes compared with fresh transfers. Fertil Steril. 2014;101(5):1294-1301.

75. Shapiro BS, Daneshmand ST, Garner FC, et al. Evidence of impaired endometrial receptivity after ovarian stimulation for in vitro fertilization: a prospective randomized trail comparing fresh and frozen-thawed embryo transfer in normal responders. Fertil Steril. 2011;96(2):344-348.

76. Liebermann J, Conaghan J. Artificial collapse prior blastocyst vitrification: improvement of clinical outcomes. J Clin Embryol. 2014;16:107-118.

77. Vanderzwalmen P, Bertin G, Debauche Ch, et al. Births after vitrification at morula and blastocyst stages: Effect of artificial reduction of the blastocoelic cavity before vitrification. Hum Reprod. 2002;17(3):744-751.

78. Panchot E, Scotino S, Carmichael C, et al. The effect of mechanically collapsing human blastocysts prior to cryopreservation. Fertil Steril (Suppl). 2004;82(2):S149-S150.

79. Stachecki JJ, Garrisi J, Sabino S, Caetano JP, Wiemer KE, Cohen J. A new safe, simple, and successful vitrification method for bovine and human blastocysts. Reprod Biomed Online. 2008;17(3):360-367.

80. Grifo JA, Hodes-Wertz B, Lee HL, Amperloquio E, Clarke-Williams M, Adler A. Single thawed euploid embryo transfer improves IVF pregnancy, miscarriage, and multiple gestation outcomes and has similar implantation rates as egg donation. J Assist Reprod Genet. 2013;30(2):259-264.

81. Whitney JB, Anderson RE, Nugent NL, Schiewe MC. Euploidy predictability of human blastocyst inner cell mass and trophectoderm grading. Ann Clin Lab Res. 2015;3:4-7.

82. Schoolcraft WB, Katz-Jaffe MG. Comprehensive chromosome screening of trophectoderm with vitrification facilitates elective single-embryo transfer for infertile women with advanced maternal age. Fertil Steril. 2013;100(3):615-619.

83. Forman EJ, Li X, Ferry KM, et al. Oocyte vitrification does not increase the risk of embryo aneuploidy or diminish the implantation potential of blastocysts created after intracytoplasmic sperm injection: a novel, paired randomized controlled trial using DNA fingerprinting. Fertil Steril. 2012;98(3):644-649. 
84. Deng A, Wang W-H. Assessment of aneuploidy formation in human blastocysts resulting from cryopreserved donor eggs. Mol Cytogenet. 2015;8:12-19.

85. Libermannn J. Vitrification of human blastocysts: clinical realities and neonatal outcomes. In: Tucker MJ, Liebermann J, editors. Vitrification in Assisted Reproduction. 2nd ed. Boca Raton: CRC Press; 2015:163-174.

86. Centers for Disease Control and Prevention. Assisted Reproductive Technology Surveillance, National Summary Reports 2010-2015. Available from: www.nccd.cdc.gov/assisted reproductive health data:clinic/DRH/CDC. Accessed August 29, 2017.

87. Gook D, Schiewe MC, Osborn SM, et al. Intracytoplasmic sperm injection and embryo development of human oocytes cryopreserved using 1,2-propanediol. Hum Reprod. 1995;10(10):2637-2641.

88. Porcu E, Fabbri R, Seracchioli R, Ciotti PM, Magrini O, Flamigni C. Birth of a healthy female after intracytoplasmic sperm injection of cryopreserved human oocytes. Fertil Steril. 1997;68(4):724-726.

89. Nawroth F, Kissing K. Pregnancy after intracytoplasmic sperm injection (ICSI) of cryopreserved human oocytes. Acta Obstet Gynecol Scand. 1998;77:462-463.

90. Tucker MJ, Wright G, Morton PC, Massey JB. Birth after cryopreservation of immature oocytes with subsequent in vitro maturation. Fertil Steril. 1998;70(3):578-579.

91. Young E, Kenny A, Puigdomenech E, Van Thillo G, Tiverón M, Piazza A. Triplet pregnancy after intracytoplasmic sperm injection of cryopreserved oocytes: case report. Fertil Steril. 1998;70(2):360-361.

92. Kuleshova L, Gianaroli L, Magli C, Ferraretti A, Trounson A. Birth following vitrification of a small number of human oocytes: case report. Hum Reprod. 1999;14(12):3077-3079.

93. Hong SW, Chung HM, Lim JM, et al. Improved human oocyte development after vitrification: a comparison of thawing methods. Fertil Steril. 1999;72(1):142-146.

94. Yoon T, Chung H, Lim J, et al. Pregnancy and delivery of healthy infants developed from vitrified oocytes in a stimulated in vitro fertilizationembryo transfer program. Fertil Steril. 2000;74(1):180-181.

95. Noyes N. Over 900 oocyte cryopreservation babies born with no apparent increase in congenital anomalies. Reprod Biomed Online. 2009;18(6):769-776.

96. Chian RC, Huang JY, Tan SL, et al. Obstetric and perinatal outcome in 200 infants conceived from vitrified oocytes. Reprod Biomed Online. 2008;16(5):608-610.

97. Practice Committee of the American Society for Reproductive Medicine; Society for Assisted Reproductive Technology. Mature oocyte cryopreservation: a guide. Fertil Steril. 2013;99(1):37-43.

98. Cobo A, Serra V, Garrido N, et al. Obstetric and perinatal outcome of babies born from vitrified oocytes. Fertil Steril. 2014;102(4):1006-1015.

99. Garcia-Velasco JA, Domingo J, Cobo A, Martínez M, Carmona L, Pellicer A. Five years' experience using oocyte vitrification to preserve fertility for medical and nonmedical indications. Fertil Steril. 2013;99(7):1994-1999.

100. Nagy ZP, Cobo A, Chang C-C. Oocyte vitrification: donor "egg banking”. In: Tucker MJ, Liebermann J, editors. Vitrification in Assisted Reproduction. 2nd ed. Boca Raton: CRC Press; 2015:129-136.

101. Cobo A, Remohí J, Chang CC, Nagy ZP. Oocyte cryopreservation for donor egg banking. Reprod Biomed Online. 2011;23(3): 341-346.

102. Rienzi L, Romano S, Albricci L, et al. Embryo development of fresh 'versus' vitrified metaphase II oocytes after ICSI: a prospective randomized sibling-oocyte study. Hum Reprod. 2010;25(1):66-73.

103.Nagy ZP. Oocyte vitrification and egg-banking. In: Schiewe MC, Fahy GM, Nagy ZP, editors. Webinar: Vitrification of Gametes, Embryos and Reproductive Tissue. Atlanta, GA: Society for Reproductive Biologists and Technologists, American Society for Reproductive Medicine; 2014.

104. Crawford S, Boulet SL, Kawwass JF, Jamieson DJ, Kissin DM. Cryopreserved oocyte versus fresh oocyte assisted reproductive technology cycles, United States, 2013. Fertil Steril. 2017;107(1):110-118.
105. Cobo A, Garrido N, Pellicer A, Remohl J. Six years' experience in ovum donation using vitrified oocytes: report of cumulative outcomes, impact of storage time, and development of a predictive model for oocyte survival rate. Fertil Steril. 2015;104(6):1426-1434.

106. Grifo JA, Noyes N. Delivery rate using cryopreserved oocytes is comparable to conventional in vitro fertilization using fresh oocytes: potential fertility preservation for female cancer patients. Fertil Steril. 2010;93(2):391-396.

107. Cobo A, Castello D, Vallejo B, et al. Outcome of cryotransfer of embryos developed from vitrified oocytes: double vitrification has no impact on delivery rates. Fertil Steril. 2013;99(6):1623-1630.

108. Chang C-C, Elliott TA, Wright G, et al. Prospective controlled study to evaluate laboratory and clinical outcomes in in vitro fertilization patients aged 30 to 39 years. Fertil Steril. 2013;99(7): 1891-1897.

109. Rienzi L, Cobo A, Paffoni A, et al. Consistent and predictable delivery rates after oocyte vitrification: an observational longitudinal cohort multicentric study. Hum Reprod. 2012;27(6):1606-1612.

110. Hosseini SM, Nasr-Esfahani MH. What does the cryopreserved oocyte look like? A fresh look at the characteristic oocyte features following cryopreservation. Reprod Biomed Online. 2016;32(4):377-387.

111. Gook DA, Edgar DH. Human oocyte cryopreservation. Hum Reprod Update. 2007;13(6):591-605.

112. Gardner DK, Sheehan CB, Rienzi L, Katz-Jaffe M, Larman MG. Analysis of oocyte physiology to improve cryopreservation procedures. Theriogenology. 2007;67(1):64-72.

113. Coticchio G, Sciajno R, Hutt K, et al. Comparative analysis of metaphase II spindle of the human oocytes through polarized light and high performance confocal microscopy. Fertil Steril. 2010;93(6):2054-2064.

114. Larman MG, Minasi MG, Rienzi L, Gardner DK. Maintenance of the meiotic spindle during vitrification in human and mouse oocytes. Reprod Biomed Online. 2007;15(6):692-700.

115. Ciotti PM, Porcu E, Notarangelo L, Magrini O, Bazzocchi A, Venturoli $\mathrm{S}$. Meiotic spindle recovery is faster in vitrification of human oocytes compared to slow freezing. Fertil Steril. 2009;91(6):2399-2407.

116. Martınez-Burgos M, Herrero L, Megias D, et al. Vitrification versus slow freezing of oocytes: effects on morphologic appearance, meiotic spindle configuration, and DNA damage. Fertil Steril. 2011;95(1):374-377.

117. Ruffing NA, Steponkus PL, Pitt PE, Parkes JE. Osmometric behavior, hydraulic conductivity, and incidence of intracellular ice formation in bovine oocytes at different developmental stages. Cryobiology. 1993;30(6):562-580.

118. Jones A, Van Blerkom J, Davis P, Toledo AA. Cryopreservation of metaphase II human oocytes effects on membrane potential: Implications for developmental competence. Hum Reprod. 2004;19(8): 1861-1866.

119. Nottola SA, Macchiarelli G, Coticchio G, et al. Ultrastructure of human mature oocytes after slow cooling cryopreservation using different sucrose concentrations. Hum Reprod. 2007;22(4):1123-1133.

120. Pelin A, Bang H, Oktay K. Age-specific probability of live birth with oocyte cryopreservation: an individual patient data meta-analysis. Fertil Steril. 2013;100(2):492-499.

121. Cobo A, García-Velasco JA, Coello A, Domingo J, Pellicer A, Remohí J. Oocyte vitrification as an efficient option for elective fertility preservation. Fertil Steril. 2016;105(3):755-764.

122. Hosseini SM, Asgari V, Hajian M, Nasr-Esfahani MH. Cytoplasmic, rather than nuclear-DNA insufficiencies as the major cause of poor competence of vitrified oocytes. Reprod Biomed Online. 2015;30(5):549-552.

123. Gosden RG, Baird DT, Wade JC, Webb R. Restoration of fertility to oophorectomized sheep by ovarian autografts stored at -196 degrees C. Hum Reprod. 1994;9:597-603.

124. Lee SJ, Schover LR, Partridge AH, et al. American Society of Clinical Oncology recommendations on fertility preservation in cancer patients. J Clin Oncol. 2006;24(18):2917-2931. 
125. Donnez J, Dolmans MM, Demylle D, et al. Live birth after orthotopic transplantation of cryopreserved ovarian tissue. Lancet. 2004;364(9443):1405-1410.

126. Donnez J, Dolmans MM, Demylle D, et al. Restoration of ovarian function after orthotopic (intraovarian and periovarian) transplantation of cryopreserved ovarian tissue in a woman treated by bone marrow transplantation for sickle cell anaemia: case report. Hum Reprod. 2006;21(1):183-188.

127. Kagawa N, Silber S, Kuwayama M. Successful vitrification of bovine and human ovarian tissue. Reprod Biomed Online. 2009;18(4):568-577.

128. Amorium CA, Dolmans MM, David A, et al. Vitrification and xenografting of human ovarian tissue. Fertil Steril. 2012;95:1094-1097.

129. Ting AY, Yeoman RR, Campos JR, et al. Morphological and functional preservation of pre-antral follicles after vitrification of macaque ovarian tissue in a closed system. Hum Reprod. 2013;28(5):1267-1279.

130. Fahy GM, Wowk B, Wu J, et al. Cryopreservation of organs by vitrification: perspectives and recent advances. Cryobiology. 2004;48(2):157-178.

131. Arav A, Revel A, Nathan Y, et al. Oocyte recovery, embryo development and ovarian function after cryopreservation and transplantation of whole sheep ovary. Hum Reprod. 2005;20(12):3554-3559.

132. Arav A, Gavish Z, Elami A, et al. . Ovarian function 6 years after cryopreservation and transplantation of whole sheep ovaries. Reprod Biomed Online. 2010;20(1):48-52.

133. Martinez-Madrid B, Camboni A, Dolmans MM, et al. Apoptosis and ultrastructural assessment after cryopreservation of whole human ovaries and their vascular pedicle. Fertil Steril. 2007;87(5):1153-1165.

134. Donnez J, Dolmans M-M. Ovarian cortex transplantation: 60 reported live births brings the success and worldwide expansion of the technique towards routine clinical practice. J Assist Reprod Genet. 2015;32(8):1167-1170.

135. Sanfilippo S, Canis M, Smitz J, et al. Vitrification of human ovarian tissue: a practical and relevant alternative to slow freezing. Reprod Biol Endocrinol. 2015;13:67-74.

136. Laronda MM, McKinnon KE, Ting AY, Le Fever AV, Zelinski MB, Woodruff TK. Good manufacturing practice requirements for the production of tissue vitrification and warming and recovery kits for clinical research. J Assist Reprod Genet. 2017;34(2):291-300.

137. Practice Committee of the American Society for Reproductive Medicine; Society for Assisted Reproductive Technology. Ovarian tissue cryopreservation: a committee opinion. Fertil Steril. 2014;101(5):1237-1243

138. Isachenko V, Isachenko E, Weiss JM, Todorov P, Kreienberg R. Cryobanking of human ovarian tissue for anti-cancer treatment: comparison of vitrification and conventional freezing. Cryo Letters. 2009;30(6):449-454.

139. Nawroth F, Isachenko V, Dessole S, et al. Vitrification of human spermatozoa without cryoprotectants. Cryo Letters. 2002;23(2):93-102.

140. Isachenko E, Isachenko V, Katkov II, et al. Vitrification of mammalian spermatozoa in the absence of cryoprotectants: from practical difficulties to present success. Reprod Biomed Online. 2003;6(2):191-200.

141. Isachenko V, Isachenko E, Katkov II, et al. Cryoprotectant-free cryopreservation of human spermatozoa by vitrification and freezing in vapor: effect on motility, DNA integrity, and fertilization ability. Biol Reprod. 2004;71(4):1167-1173.
142. Isachenko E, Isachenko V, Katkov II, et al. DNA integrity and motility of human spermatozoa after standard slow freezing versus cryoprotectant-free vitrification. Hum Reprod. 2004;19(4): 932-939.

143. Isachenko V, Isachenko E, Montag M, et al. Clean technology for cryoprotectant-free vitrification of human spermatozoa. Reprod Biomed Online. 2005;10(3):350-354.

144. Isachenko E, Isachenko V, Weiss JM, et al. Acrosomal status and mitochondrial activity of human spermatozoa vitrified with sucrose. Reproduction. 2008;136(2):167-173.

145. Isachenko V, Maettner R, Petrunkina AM, et al. Vitrification of human ICSI/IVF spermatozoa without cryoprotectants: new capillary technology. J Androl. 2012;33(3):462-468.

146. Kuznyetsov V, Moskovtsev SI, Crowe M, Lulat AG, Librach CL. Vitrification of a small number of spermatozoa in normozoospermic and severely oligozoospermic samples. Syst Biol Reprod Med. 2015;61(1):13-17.

147. Isachenko E, Mallmann $\mathrm{P}$, Rahimi $\mathrm{G}$, et al. Vitrification technique - new possibilities for male gamete low temperature storage. In: Katkov II, editor. Frontiers in Cryobiology. Croatia: InTech; 2012:41-76.

148. Agha-Rahimi A, Khalili MA, Nabi A, Ashourzadeh S. Vitrification is not superior to rapid freezing of normozoospermic spermatozoa: effects on sperm parameters, DNA fragmentation and hyaluronan binding. Reprod Biomed Online. 2014;28(3):352-358.

149. Mansilla MA, Merino O, Risopatrón J, Isachenko V, Isachenko E, Sánchez R. High temperature is essential for preserved human sperm function during the devitrification process. Andrologia. 2015; 48(1):1-3.

150. Isachenko V, Isachenko E, Petrunkina AM, Sanchez R. Human spermatozoa vitrified in the absence of permeable cryoprotectants: birth of two healthy babies. Reprod Fertil Dev. 2011;24(2): 323-326

151. Sánchez R, Isachenko V, Petrunkina AM, et al. Live birth after intrauterine insemination with spermatozoa from an oligo-asthenozoospermic patient vitrified without permeable cryoprotectants. J Androl. 2011;33(4):559-562.

152. Sánchez R, Risopatrón J, Schulz M, et al. Vitrified sperm banks: the new aseptic technique for human spermatozoa allows cryopreservation at $-86^{\circ}$ C. Andrologia. 2012;44(6):433-435.

153. Moskovtsev SI, Lulat AG-M, Librach CL. Cryopreservation of human spermatozoa by vitrification vs slow freezing: Canadian experience. In: Katkov II, editor. Frontiers in Cryobiology. Croatia: InTech; 2012:79-100.

154. Slabbert M, du Plessis SS, Huyser C. Large volume cryoprotectantfree vitrification: an alternative to conventional cryopreservation for human spermatozoa. Andrologia. 2015;47(5):594-599.

155. Wyns C, Abou-Ghannam G, Poels J. Vitrification of human testicular tissue, spermatogonia, and spermatozoa. In: Tucker MJ, Liebermann J, editors. Vitrification in Assisted Reproduction. 2nd ed. Boca Raton: CRC Press; 2015:197-202.

156. Schiewe MC, Rothman C, Spitz A, et al. Validation-verification of a highly effective, practical human testicular tissue in vitro culture -cryopreservation procedure aimed at optimizing pre-freeze and postthaw motility. J Assist Reprod Genet. 2016;33:519-528.
Journal of Biorepository Science for Applied Medicine

\section{Publish your work in this journal}

The Journal of Biorepository Science for Applied Medicine is an international, peerreviewed, open access journal that focuses on new developments and advances in the emerging and evolving field of biorepository science. This includes biospecimen procurement, processing, preservation, and banking for application to applied medicine. The Journal invites submission of manuscripts which address these aspects in addition to systems logic, clinical throughput and ethical issues pertaining to application of

\section{Dovepress}

biorepositories and their effects on clinical medicine. The journal is characterized by the rapid reporting of reviews, original research, methodologies, technologies and analytics in this subject area. The manuscript management system is completely online and includes a very quick and fair peer-review system, which is all easy to use. Visit http:// www.dovepress.com/testimonials.php to read real quotes from published authors. 